\title{
REGIONAL FLOOD RISK ANALYSIS FOR HUAIHONG SOUTH FLOOD CONTROL PROTECTED AREA IN CHINA USING AN INTEGRATED METHOD
}

\author{
GAO, Y. Q. $.^{*}-$ ZHOU, X. ${ }^{1}-$ ZHANG, Z. X. ${ }^{2}$ \\ ${ }^{1}$ College of Water Conservancy and Hydropower Engineering, Hohai University, No. 1 Xikang \\ Road, Gulou District, Nanjing 210098, China \\ ${ }^{2}$ Illionis State Water Survey, Prairie Research Institute, University of Illinois Urbana- \\ Champaign, 2204 Griffith Dr., Champaign IL, USA \\ *Corresponding author \\ e-mail: gyq_0909@163.com; phone: +86-139-5188-9955
}

(Received 27 $7^{\text {th }}$ Sep 2019; accepted $4^{\text {th }}$ Feb 2020)

\begin{abstract}
Non-engineering flood control measures have gradually become an important part of flood disaster management in the past decades, and it cannot be separated from regional flood risk analyses. Flood risk analyses can be regarded as a complex of three aspects: flood hazard analyses, vulnerability analyses and comprehensive evaluation of both. In this paper, taking Huaihong South Flood Control Protected Area (simplified as HHS) of the Huaihe River Basin in China as an example, a one-dimensional (1-D) and two-dimensional (2-D) coupled hydrodynamic model of the study area was established to simulate the evolution process of the floods with different return periods and acquire inundation data in the flood hazard analysis. Concerning the vulnerability analysis, based on the composition mechanism of vulnerability and the available data of the study region, the vulnerability evaluation index system was established, then the magnitudes of vulnerability of the townships in the research were analyzed through the catastrophe progression method. Combined with the analysis results above, the flood risk of 15 townships in HHS can be classified into 6 magnitudes by factor analysis and hierarchical clustering analysis. The results show that the flood risk is medium or even higher in most zones of HHS. The integrated method used in this research can also be applied to other regions.
\end{abstract}

Keywords: flood risk, vulnerability analysis, 1-D and 2-D coupled hydrodynamic model, catastrophe progression method, factor analysis, hierarchical clustering analysis

\section{Introduction}

In recent decades, with the climatic changes, population growth and urban development in flood-prone areas, the ability of human beings to control floods has become stronger and stronger, but the devastating impacts on people's livelihood, economy and the environment due to floods had an increasing tendency in the past 25 years in China (Yu et al., 2018). A possible way to reduce the loss of flood disasters is the mapping of flood-prone areas to risk awareness and support sustainable land-use planning and urban development (Horritt et al., 2007). Flood risk analysis is a useful source of information in rescue and relief agencies for their operations. In 2007, the European Union has adopted Flood Directive, with the main objective of reducing and managing flood risk (Van Alphen et al., 2009).

Flood risk analyses can be basically divided into three parts: flood hazard analyses, vulnerability analyses and comprehensive evaluation of both. The researches on flood hazard analyses at domestic and abroad generally include two aspects: one is to explore the inner relationship between the different return periods and the actual scales of flood events; the other one is to predict future flow regime characteristics in flood-affected 
areas, and the flood hazard has usually been expressed by inundation information of flood (inundation range, depth, duration, etc.). The aim of vulnerability analyses is to assess the multi-dimensional vulnerability (Physical, Social, Economic and Environment) of the region. This exercise will be used to develop a vulnerability map as an input towards flood risk analysis.

In scientific literature, for both the hazard and vulnerability analyses, a number of approaches and models of different complexity levels are available (Kourgialas and Karatzas, 2011). Kourgialas and Karatzas (2011) presented a method to estimate the flood-hazard areas considering six factors: flow accumulation, slope, land use, rainfall intensity, geology and elevation. The study area was divided into five regions characterized by different magnitudes of flood risk ranging from very low to extremely high. Apel et al. (2009) tested numerous combinations of models of different complexity both on the hazard and on the vulnerability side in a case study. On the hazard side, the models selected include a mixed 1D/2D hydraulic model. On the vulnerability side, the models used for the estimation of direct damage to residential buildings are in order of increasing complexity, such as a rule-based micro-scale model applied to a detailed building inventory (Apel et al., 2011).

\section{Materials and methods}

\section{Study area}

The riverine area of the Huaihe River Basin in the Anhui Province (in China) has always been prone to flooding disasters (Wang, 2015). One of the most serious flooding areas in the Anhui Province is HHS which is located between $32^{\circ} 50^{\prime} \mathrm{N}-33^{\circ} 20^{\prime} \mathrm{N}$ latitude and $117^{\circ} 10^{\prime} \mathrm{E}-117^{\circ} 50^{\prime} \mathrm{E}$ longitude, covering an area of about $1480 \mathrm{~km}^{2}$ (Fig. 1). It covers 15 townships in three counties, one district. The general trend of HHS is higher in the north and lower in the south.

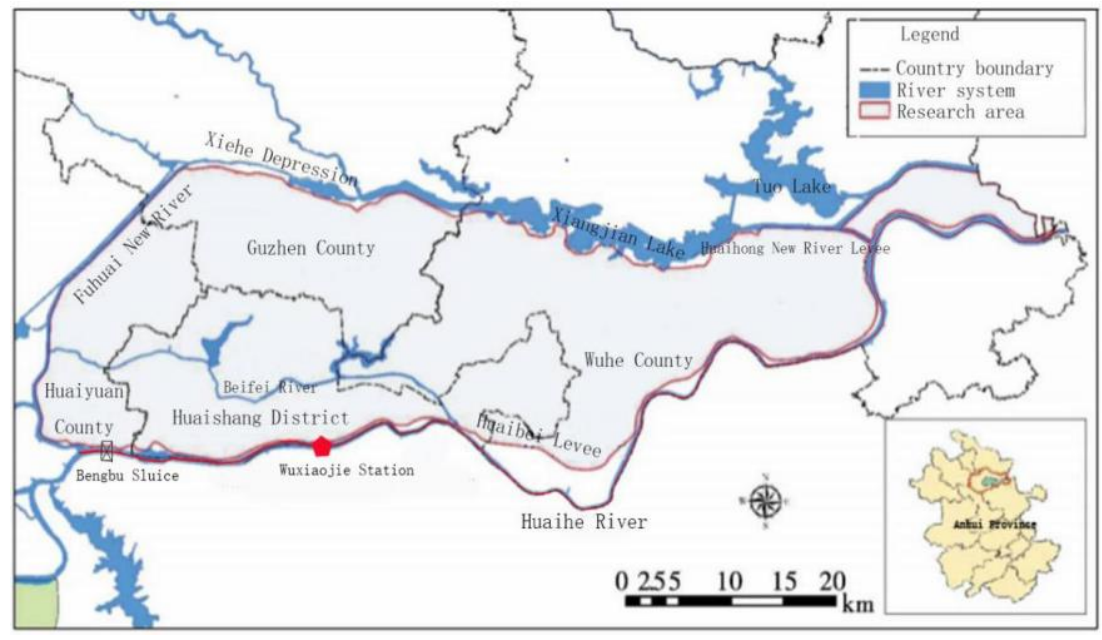

Figure 1. Location of HHS

\section{Available data}

The topographic data used in this research is based on 1:10000 topographic data and the DEM of the entire study area with a horizontal resolution of $5 \mathrm{~m}$ provided by Anhui 
Provincial Flood Control Office. Topographic map of the research region is shown in Figure 2. The cross-sectional data of the main stream of the Huaihe River are 104 crosssections with 1-2 km spacing between the cross-sections measured in 1993.

Total length of the river reach in study is $110.0 \mathrm{~km}$. Discharge curves of $50-, 100-$ and 200-year floods in Wujiadu Station are available (Fig. 3). Generalized river network of main stream of the Huaihe River considered in this research is shown in Figure 4.

According to the information sheet of key dangerous sections provided by the relevant water conservancy department, the Wuxiaojie Station on the Huaibei levee (indicated in Fig. 1) is selected as the possible dyke burst. Table 1 shows the data of evaluation indicators (refer to Statistical Yearbook of Bengbu City in 2015) used in this research.

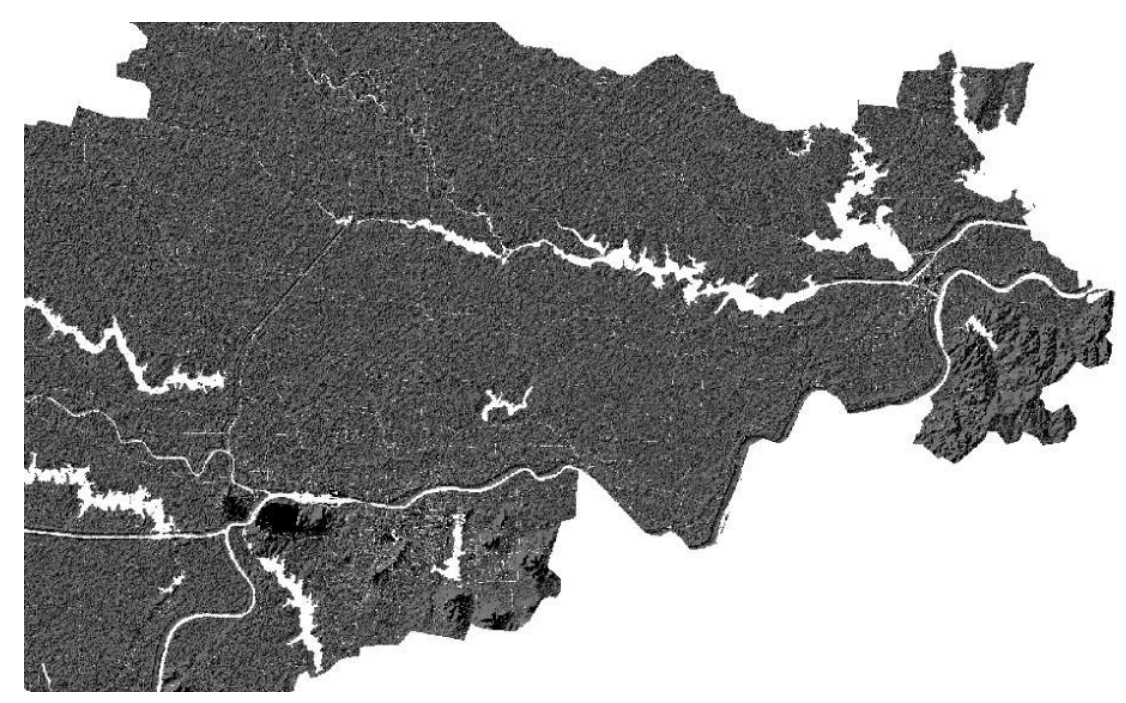

Figure 2. Topographic map of the entire study area

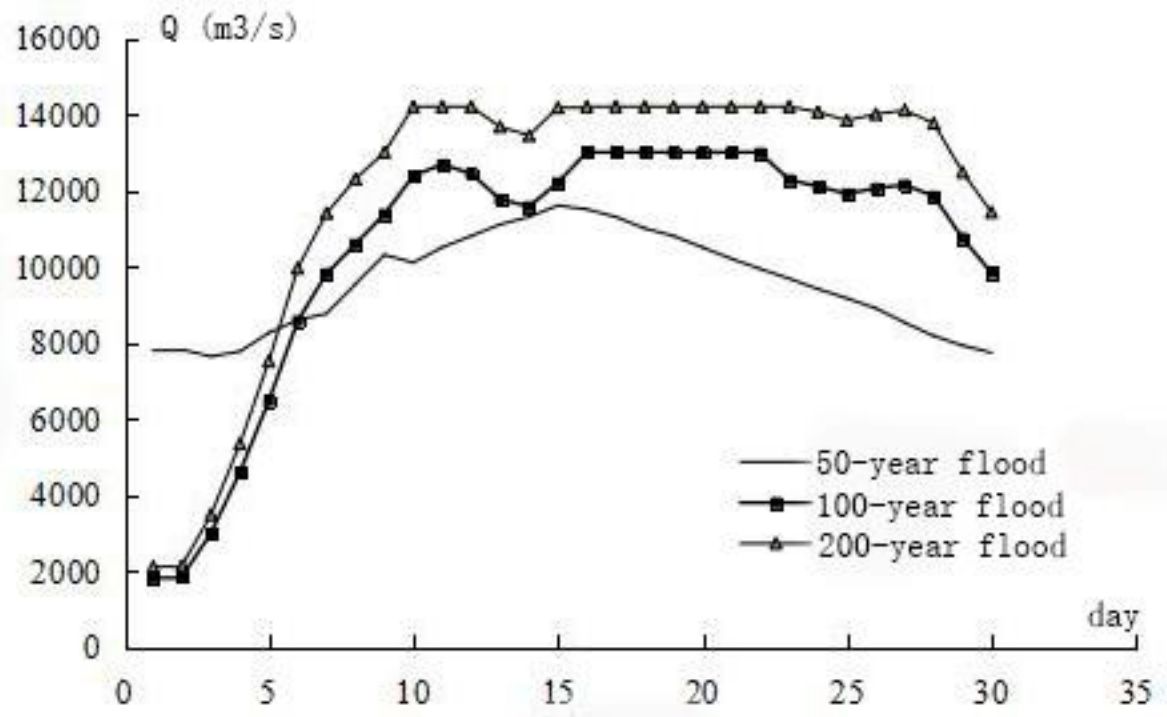

Figure 3. Discharge curves of 50-, 100- and 200-year floods in Wujiadu Station 


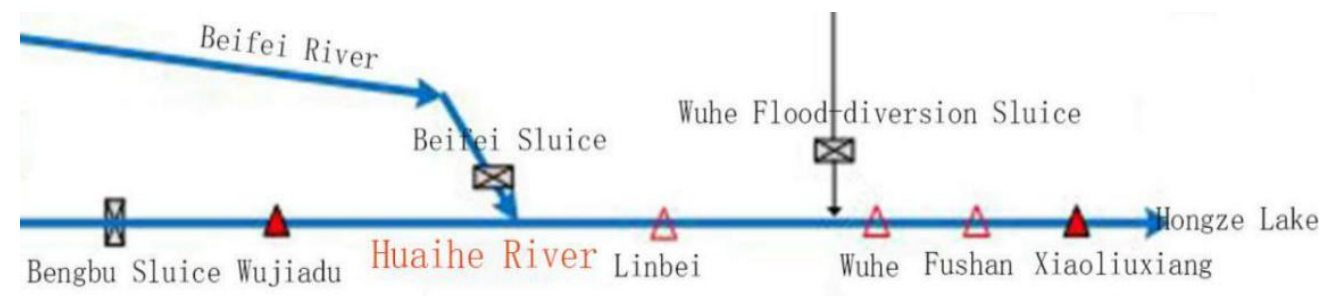

Figure 4. Generalized river network of main stream of the Huaihe River considered in this research

Table 1. Original values of indicators used in this research

\begin{tabular}{|c|c|c|c|c|c|}
\hline \multirow[b]{2}{*}{ Indicator } & \multicolumn{5}{|c|}{ Evaluation township } \\
\hline & Huinan (HN) & Xinji (XJ) & Toupu (TP) & Daxin (DX) & $\begin{array}{l}\text { Caoguzhang } \\
\text { (CGZ) }\end{array}$ \\
\hline $\begin{array}{l}\text { Drainage density } \\
\qquad\left(\mathrm{m} / 10^{3} \mathrm{~m}^{2}\right)\end{array}$ & 0.007 & 0.008 & 0.008 & 0.006 & 0.008 \\
\hline $\begin{array}{l}\text { GDP per unit area } \\
\left(\text { million } / 10^{6} \mathrm{~m}^{2}\right)\end{array}$ & 904.597 & 1351.741 & 1043.725 & 1160.379 & 1152.572 \\
\hline $\begin{array}{l}\text { Density of population } \\
\quad\left(\text { person } / 10^{6} \mathrm{~m}^{2}\right)\end{array}$ & 296.004 & 449.046 & 505.887 & 461.485 & 184.241 \\
\hline $\begin{array}{l}\text { Density of residential } \\
\text { structures }\left(\mathrm{m}^{2} / \mathrm{m}^{2}\right)\end{array}$ & 0.014 & 0.021 & 0.023 & 0.022 & 0.007 \\
\hline $\begin{array}{l}\text { Density of lifeline engineering } \\
\text { structures }\left(\mathrm{m} / 10^{3} \mathrm{~m}^{2}\right)\end{array}$ & 0.407 & 0.482 & 0.593 & 0.512 & 0.271 \\
\hline $\begin{array}{c}\text { Proportion of agricultural } \\
\text { population }(\%)\end{array}$ & 0.964 & 0.941 & 0.962 & 0.964 & 0.828 \\
\hline $\begin{array}{c}\text { Average } \\
\text { elevation }(\mathrm{m})\end{array}$ & 18.176 & 16.136 & 15.076 & 16.625 & 17.446 \\
\hline $\begin{array}{l}\text { Land-use sensitive } \\
\text { index }\end{array}$ & 4.119 & 4.063 & 4.2 & 3.275 & 4.336 \\
\hline $\begin{array}{l}\text { Proportion of female } \\
\text { population }(\%)\end{array}$ & 0.468 & 0.47 & 0.478 & 0.473 & 0.485 \\
\hline $\begin{array}{l}\text { GDP per capital } \\
\text { (million/person) }\end{array}$ & 2.663 & 2.64 & 1.882 & 2.219 & 6.256 \\
\hline $\begin{array}{l}\text { Density of shelters } \\
\left(\text { number } / 10^{6} \mathrm{~m}\right)\end{array}$ & 0.288 & 0.03 & 0.101 & 0.146 & 0.083 \\
\hline $\begin{array}{l}\text { Density of medical aid } \\
\text { institutions (one } / 10^{6} \mathrm{~m}^{2} \text { ) }\end{array}$ & 0.09 & 0.296 & 0.172 & 0.255 & 0.193 \\
\hline \multirow[b]{2}{*}{ Indicator } & \multicolumn{5}{|c|}{ Evaluation township } \\
\hline & $\begin{array}{l}\text { North of the } \\
\text { Muslim (NM) }\end{array}$ & $\begin{array}{l}\text { Xinmaqiao } \\
\text { (XMQ) }\end{array}$ & \begin{tabular}{|c|} 
Wangzhuang \\
(WZ)
\end{tabular} & $\begin{array}{c}\text { Meiqiao } \\
\text { (MQ) }\end{array}$ & Caolaoji (CLJ) \\
\hline $\begin{array}{l}\text { Drainage density } \\
\qquad\left(\mathrm{m} / 10^{3} \mathrm{~m}^{2}\right)\end{array}$ & 0.017 & 0.007 & 0.007 & 0.008 & 0.009 \\
\hline $\begin{array}{l}\text { GDP per unit area } \\
\left(\text { million } / 10^{6} \mathrm{~m}^{2}\right)\end{array}$ & 531.921 & 1285.729 & 1047.172 & 3926.926 & 2652.742 \\
\hline $\begin{array}{l}\text { Density of population } \\
\left(\text { person } / 10^{6} \mathrm{~m}^{2}\right)\end{array}$ & 185.198 & 359.764 & 355.156 & 805.851 & 530.141 \\
\hline $\begin{array}{l}\text { Density of residential } \\
\text { structures }\left(\mathrm{m}^{2} / \mathrm{m}^{2}\right)\end{array}$ & 0.007 & 0.014 & 0.013 & 0.031 & 0.021 \\
\hline $\begin{array}{l}\text { Density of lifeline engineering } \\
\text { structures }\left(\mathrm{m} / 10^{3} \mathrm{~m}^{2}\right)\end{array}$ & 1.62 & 0.631 & 0.343 & 0.685 & 0.473 \\
\hline $\begin{array}{l}\text { Proportion of agricultural } \\
\text { population }(\%)\end{array}$ & 0.862 & 0.946 & 0.968 & 0.93 & 0.951 \\
\hline
\end{tabular}




\begin{tabular}{|c|c|c|c|c|c|}
\hline $\begin{array}{c}\text { Average } \\
\text { Elevation (m) }\end{array}$ & 17.257 & 19.193 & 18.905 & 17.277 & 17.288 \\
\hline $\begin{array}{l}\text { Land-use sensitive } \\
\text { index }\end{array}$ & 3.265 & 4.27 & 4.167 & 3.623 & 3.967 \\
\hline $\begin{array}{l}\text { Proportion of female } \\
\text { population }(\%)\end{array}$ & 0.465 & 0.475 & 0.466 & 0.459 & 0.477 \\
\hline $\begin{array}{l}\text { GDP per capital } \\
\text { (million/person) }\end{array}$ & 2.872 & 3.274 & 2.774 & 4.873 & 5.004 \\
\hline $\begin{array}{l}\text { Density of shelters } \\
\left.\text { (number } / 10^{6} \mathrm{~m}\right)\end{array}$ & 0.081 & 0.061 & 0.037 & 0.298 & 0.104 \\
\hline $\begin{array}{l}\text { Density of medical aid } \\
\text { institutions (one } / 10^{6} \mathrm{~m}^{2} \text { ) }\end{array}$ & 0.228 & 0.155 & 0.203 & 0.265 & 0.166 \\
\hline & \multicolumn{5}{|c|}{ Evaluation township } \\
\hline Indicator & $\begin{array}{l}\text { Wuxiaojie } \\
\text { (WXJ) }\end{array}$ & $\begin{array}{l}\text { Xiaobengbu } \\
\text { (XBB) }\end{array}$ & $\begin{array}{l}\text { Mohekou } \\
\text { (MHK) }\end{array}$ & $\begin{array}{l}\text { Weizhuang } \\
\text { (WEZ) }\end{array}$ & $\begin{array}{l}\text { Chengguan town } \\
\text { in Huaiyuan } \\
\text { county (CG) }\end{array}$ \\
\hline $\begin{array}{l}\text { Drainage density } \\
\qquad\left(\mathrm{m} / 10^{3} \mathrm{~m}^{2}\right)\end{array}$ & 0.008 & 0.006 & 0.006 & 0.008 & 0.013 \\
\hline $\begin{array}{l}\text { GDP per unit area } \\
\left(\text { million } / 10^{6} \mathrm{~m}^{2}\right)\end{array}$ & 17638.226 & 62040.981 & 3567.112 & 254.26 & 14918.667 \\
\hline $\begin{array}{l}\text { Density of population } \\
\quad\left(\text { person } / 10^{6} \mathrm{~m}^{2}\right)\end{array}$ & 757.459 & 1217.154 & 707.183 & 125.8 & 691.251 \\
\hline $\begin{array}{l}\text { Density of residential } \\
\text { structures }\left(\mathrm{m}^{2} / \mathrm{m}^{2}\right)\end{array}$ & 0.031 & 0.051 & 0.029 & 0.01 & 0.053 \\
\hline $\begin{array}{l}\text { Density of lifeline engineering } \\
\text { structures }\left(\mathrm{m} / 10^{3} \mathrm{~m}^{2}\right)\end{array}$ & 1.258 & 1.843 & 0.604 & 1.027 & 2.324 \\
\hline $\begin{array}{l}\text { Proportion of agricultural } \\
\text { population }(\%)\end{array}$ & 0.7 & 0.336 & 0.947 & 0.967 & 0.22 \\
\hline $\begin{array}{c}\text { Average } \\
\text { elevation (m) }\end{array}$ & 16.991 & 17.656 & 17.492 & 18.281 & 18.67 \\
\hline $\begin{array}{l}\text { Land-use sensitive } \\
\text { index }\end{array}$ & 3.662 & 3.146 & 4.367 & 2.847 & 2.831 \\
\hline $\begin{array}{l}\text { Proportion of female } \\
\text { population }(\%)\end{array}$ & 0.501 & 0.506 & 0.478 & 0.47 & 0.493 \\
\hline $\begin{array}{l}\text { GDP per capital } \\
\text { (million/person) }\end{array}$ & 21.843 & 44.59 & 4.749 & 1.038 & 10.435 \\
\hline $\begin{array}{l}\text { Density of shelters } \\
\left(\text { number } / 10^{6} \mathrm{~m}\right)\end{array}$ & 0.474 & 1.834 & 0.347 & 0.108 & 1.226 \\
\hline $\begin{array}{l}\text { Density of medical aid } \\
\text { institutions (one } / 10^{6} \mathrm{~m}^{2} \text { ) }\end{array}$ & 0.422 & 0.386 & 0.163 & 0.118 & 0.2 \\
\hline
\end{tabular}

\section{Flood hazard analysis}

Flood hazard analysis is one of the methods of flood forecasting. In this paper, a 1-D hydrodynamic model was used to simulate the flood course of Huaihe River in the study area, a 2-D hydrodynamic model was used to simulate the flood routing in HHS, and a 1-D and 2-D coupled hydrodynamic model was used to simulate the flood course of a levee breach (Zhang et al., 2019). MIKE software with the advantage of stability, reliability and high accuracy was selected for modelling calculation.

\section{1-D hydrodynamic modelling}

For the 1-D hydrodynamic modelling, in terms of topographic data, it required a certain number of cross-sections to represent the river channel and its surrounding 
topography (Cook and Merwadee, 2009). The 104 cross-sections measured in 1993 were used in the model for describing the geometry of the river reach. Considering Wuxiaojie Station was the breach of Huaibei levee, the discharge curves of 50-, 100and 200-year floods at the breach were taken as the upstream boundary condition, whereas the stage-discharge relation at Xiaoliuxiang Station was used as the downstream boundary condition (Brandimarte and Di Baldassarre, 2012). The 1-D model was established to simulate floods in the one-dimensional channel from Bengbu Sluice to Xiaoliuxiang Station with MIKE 11 (Ferdous, 2012). The initial discharge of the river is set to 0 , and the initial water level is set to the measured water level at the beginning of the simulation.

\section{2-D hydrodynamic modelling}

The domain of the 2-D hydrodynamic model is described by a mesh consisting of nodes and triangular elements (Tewodros and Abdusselam, 2019; Jungkyu et al., 2019). The topographic data adopted in this model was the 1:10000 topographic data and DEM of the entire study area with a horizontal resolution of $5 \mathrm{~m}$. In this model, a hybrid grid model was established to reflect the overall terrain variation characteristics of the region. The 2-D model was used to simulate the flood routing in HHS with MIKE 21.

\section{1-D and 2-D coupled hydrodynamic modelling}

The 1-D and 2-D coupled hydrodynamic model simulated the 1-D flow in river channels and the 2-D flow in floodplains with MIKE FLOOD to acquire inundation depth, inundation duration and velocity of the floods with different recurrence periods (Parto et al., 2009). During the coupling process, the left embankment of Huaihe River, the right embankment of Huaihong New River and the $20.5 \mathrm{~m}$ contour line of Fengshan in Sihong County of Jiangsu Province in China were taken as the external boundary; the dispatching process of dikes, roads, bridges, culverts and other structures were used as the internal boundary conditions. The 1-D model and 2-D model exchanged water level and flow information with each other. The 1-D model used the water level of the 2-D model's grid at the coupling point as the boundary water level, whereas the 2-D model used the outflow of the 1-D model at the coupling point as the inflow.

\section{Vulnerability analysis}

\section{Vulnerability index system}

In this study, vulnerability of the evaluation object at flood risk is regarded as a state variable. In the absence of a thorough study on the formation mechanism of vulnerability to flood, the index system method which is based on the hierarchy and the correlation between structural indicators of vulnerability is the most common method. It can reflect the overall macro-situation of the magnitudes of flood vulnerability in the region (Fan et al., 2000).

Defined as the inherent attribute of an element at risk, vulnerability was usually composed of three parts: exposure degree (Baldassarre et al., 2009), sensitivity, capacity of disaster prevention and mitigation. According to this, representative indicators (Table 2) are selected to construct the vulnerability index system of the evaluation object at flood risk. 
Table 2. Vulnerability index system of the evaluation object at flood risk

\begin{tabular}{|c|c|c|}
\hline Target layer & Criterion layer & Index layer \\
\hline \multirow{11}{*}{$\begin{array}{l}\text { Vulnerability } \\
\text { (A) }\end{array}$} & \multirow{4}{*}{ Exposure degree (B1) } & GDP per unit area $(\mathrm{C} 1)$ \\
\hline & & Density of population (C2) \\
\hline & & Density of residential structures (C3) \\
\hline & & Density of lifeline engineering structures (C4) \\
\hline & \multirow{4}{*}{ Sensibility (B2) } & Average elevation (C5) \\
\hline & & Proportion of agricultural population (C6) \\
\hline & & Land-use sensitive index (C7) \\
\hline & & Proportion of female population (C8) \\
\hline & \multirow{3}{*}{$\begin{array}{l}\text { Capacity of disaster prevention and } \\
\text { mitigation (B3) }\end{array}$} & GDP per capital (C9) \\
\hline & & Density of shelters $(\mathrm{C} 10)$ \\
\hline & & Density of medical aid institutions (C11) \\
\hline
\end{tabular}

Among these indicators, GDP per unit area refers to the gross domestic product of agriculture, industry and tertiary industry; density of lifeline engineering structures refers to the lifeline length per unit area; land use sensitive index is defined in the literature (Chen et al., 2012); density of shelters refers to the number of large and medium-sized sites, such as schools, shopping malls and hotels, that can accommodate the affected people on unit area of the evaluation township; density of medical aid institutions refers to the number of medical aid institutions on unit area of the evaluation township.

\section{Catastrophe progression method}

In order to avoid the subjectivity of determining the weight assignment of vulnerability indicators, this study used the catastrophe progression method to evaluate the magnitudes of vulnerability to flood of the townships in the region ( $\mathrm{Li}$ et al., 2010; Liu et al., 2010).

When calculating the vulnerability indicators of evaluation townships, the original values of indicators in the Table 1 should be uniformly normalized and transformed into positive indices in the range of $[0,1]$.

For the larger-the-better indices:

$$
r_{i j}=\frac{x_{i j}-\min \left(x_{i j}\right)}{\max \left(x_{i j}\right)-\min \left(x_{i j}\right)}
$$

For the smaller-the-better indices:

$$
r_{i j}=\frac{\max \left(x_{i j}\right)-x_{i j}}{\max \left(x_{i j}\right)-\min \left(x_{i j}\right)}
$$

where $\mathrm{x}_{\mathrm{ij}}$ - original value of index ' $\mathrm{j}$ ' of evaluation township ' $\mathrm{i}$ '; $\max \left(\mathrm{x}_{\mathrm{ij}}\right)$ and $\min \left(\mathrm{x}_{\mathrm{ij}}\right)-$ maximum and minimum value of index ' $\mathrm{j}$ '; $\mathrm{r}_{\mathrm{ij}}$ - normalized value of $\mathrm{x}_{\mathrm{ij}}$. 
Catastrophe progression method is a multilevel objective decomposition for evaluation objects which combing the catastrophe theory and fuzzy mathematics, the ultimate catastrophe function is obtained through quantitative computing by the normalization formula of different catastrophe models, and thus the comprehensive assessment of alternatives is realized, then a catastrophe progression model is obtained to classify the vulnerability classification of evaluation townships.

In this paper, according to the number of variables, we chose the proper catastrophe progression model and used the corresponding normalization formula layer by layer to calculate until the ultimate catastrophe functional value (value of vulnerability to flood) was obtained. The mean value was taken as the upper index value when calculating the catastrophe progression of each layer for the reason that the evaluation indices considered in this study could make up for their deficiencies. Alternative catastrophic models are shown in Table 3 (Li et al., 2010).

Table 3. Alternative catastrophe progression models.

\begin{tabular}{c|c|c}
\hline Catastrophe progression model & Number of variables & Normalization formula \\
\hline Cusp catastrophe & 2 & $\mathrm{X}_{\mathrm{a}}=\mathrm{a}^{1 / 2} ; \mathrm{X}_{\mathrm{b}}=\mathrm{b}^{1 / 3}$ \\
Swallowtail catastrophe & 3 & $\mathrm{X}_{\mathrm{a}}=\mathrm{a}^{1 / 2} ; \mathrm{X}_{\mathrm{b}}=\mathrm{b}^{1 / 3} ; \mathrm{X}_{\mathrm{c}}=\mathrm{c}^{1 / 4}$ \\
Butterfly catastrophe & 4 & $\mathrm{X}_{\mathrm{a}}=\mathrm{a}^{1 / 2} ; \mathrm{X}_{\mathrm{b}}=\mathrm{b}^{1 / 3} ; \mathrm{X}_{\mathrm{c}}=\mathrm{c}^{1 / 4} ; \mathrm{X}_{\mathrm{d}}=\mathrm{d}^{1 / 5}$ \\
\hline
\end{tabular}

$\mathrm{X}_{\mathrm{a}}, \mathrm{X}_{\mathrm{b}}, \mathrm{X}_{\mathrm{c}}, \mathrm{X}_{\mathrm{d}}$ - catastrophe progression of a, b, c, d; a, b, c, d-normalized values of indices

\section{Risk analysis}

\section{Flood risk index system}

In a flood risk index system, according to the process of flood hazard analysis and vulnerability analysis (Fuchs et al., 2012; Merz et al., 2010; Masood and Takeuchi, 2012), inundation depth, inundation duration and velocity of 200-year flood were selected as indicators of flood hazard, drainage density, proportion of agricultural population, proportion of female population, land-use sensitive index, GDP per unit area, density of population, density of residential structures, density of lifeline engineering structures, GDP per capital and density of shelters were taken as vulnerability indicators.

\section{Factor analysis}

In the study of flood risk assessment, it generally involves multiple evaluation indicators and numerous evaluation objects ( $\mathrm{Li}$ et al., 2003). Attempting to synthesize the characteristics reflected by various indicators and minimize the loss of raw information, we transformed several evaluation indicators into a few comprehensive factors through factor analysis (Helena et al., 2003). The basic idea of factor analysis approach is to divide the original indicator variables into several groups by making the correlation of variables in the same group become higher, while the correlation of variables from different groups become lower. Each group of indicator variables can be represented by an immeasurable comprehensive variable which is also called a common factor (Kuo et al., 2013). In this way, a few representative common factors can be used to summarize the information provided by the original variables (Muangthong and Shrestha, 2015). The part of the original variables which cannot be explained by the 
common factors will be regarded as special factors (Wan et al., 2013). It can be expressed by mathematical formula as follows (Ma et al., 2011; Zhang et al., 2009).

$$
\begin{aligned}
& x_{1}=a_{11} F_{1}+a_{12} F_{2}+\cdots+a_{1 m} F_{m}+\varepsilon_{1} \\
& x_{2}=a_{21} F_{1}+a_{22} F_{2}+\cdots+a_{2 m} F_{m}+\varepsilon_{2} \\
& \cdots \\
& x_{p}=a_{p 1} F_{1}+a_{p 2} F_{2}+\cdots+a_{p m} F_{m}+\varepsilon_{p}
\end{aligned}
$$

where $x_{i}(i=1,2, \ldots, p)$ - original indicator variable; $F_{j}(j=1,2, \ldots, m)-$ common factor; $\mathrm{a}_{\mathrm{ij}}(\mathrm{i}=1,2, \ldots, \mathrm{p} ; \mathrm{j}=1,2, \ldots, \mathrm{m})-$ load of common factor $\mathrm{F}_{\mathrm{j}}$ on variable $\mathrm{x}_{\mathrm{i}} ; \varepsilon_{i}(i=1,2, \ldots, p)$ - special factor.

$F_{j}(j=1,2, \ldots, m)$ can be represented as follows:

$$
F=B X \Leftrightarrow \begin{aligned}
& F_{1}=b_{11} x_{1}+b_{12} x_{2}+\ldots+b_{1 p} x_{p} \\
& F_{2}=b_{21} x_{1}+b_{22} x_{2}+\ldots+b_{2 p} x_{p} \\
& \ldots \\
& F_{m}=b_{m 1} x_{1}+b_{m 2} x_{2}+\ldots+b_{m p} x_{p}
\end{aligned}
$$

where $\mathrm{x}_{\mathrm{i}}(\mathrm{i}=1,2, \ldots, \mathrm{p})$ - standardized variable; $\mathrm{B}$ - factor loading matrix.

Calculating the score ' $S$ ' of each evaluation unit:

$$
S=\sum_{i=1}^{m}\left[\left(F_{i} \times\left(C_{i} / C\right)\right]\right.
$$

where $\mathrm{C}_{\mathrm{i}}(\mathrm{i}=1,2, \ldots, \mathrm{m})$ - contribution of variances of each common factor; $\mathrm{C}$ accumulated contribution of variances.

\section{Hierarchical clustering analysis}

The evaluation objects are further classified by clustering to reveal the internal relationship among multiple evaluation objects with the method of hierarchical clustering algorithm in this research. Suppose there are ' $n$ ' samples to be clustered, for hierarchical clustering, the steps are as follows:

Step1: Initialization (take each sample as a class, and calculate the distance between each two classes, that is, the similarity between samples).

Step2: Find the two nearest classes among these classes, and classify them into one class (so that the total number of classes is one less).

Step3: Recalculate the similarity between the newly generated class and each old class.

Step4: Repeat Step2 and Step3 until all samples are in the same category.

Using MATLAB to perform the steps above can obtain the clustering dendrogram of hierarchical clustering analysis like Figure 5.

Based on clustering 15 samples (taking the comprehensive flood risk score ' $S$ ' and the vulnerability index value of one township as a sample) by the hierarchical clustering method, the townships falling in HHS were divided into various flood risk zones 
namely extremely-high-, high-, medium-high-, medium-, low-medium- and low-risk zones, taking township as a stratum.

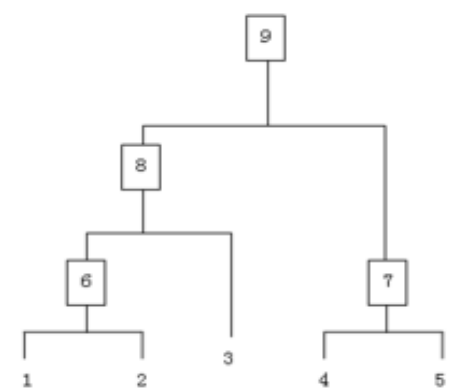

Figure 5. Generalized dendrogram of Hierarchical clustering analysis

\section{Results}

\section{Flood hazard}

A simulation was conducted according to the above-mentioned model (the 1-D and 2-D coupled hydrodynamic model) by MIKE software, the simulation inundation data based on the 50-year, 100-year and 200-year return period floods are presented in Table 4.

Table 4. Simulation inundation data based on the 50-year, 100-year and 200-year return period flood

\begin{tabular}{c|c|c|c|c|c|c|c|c|c|c}
\hline \multirow{2}{*}{$\begin{array}{c}\text { Evaluation } \\
\text { township }\end{array}$} & \multicolumn{3}{|c|}{ Inundation depth $(\mathbf{m})$} & \multicolumn{3}{c|}{ Inundation duration $(\mathbf{h})$} & \multicolumn{3}{c}{ Flood velocity (m/s) } \\
\hline 50-yer & 100-year & 200-year & 50-year & 100-year & 200-year & 50-year & 100-year & 200-year \\
HN & 0.684 & 1.808 & 2.181 & 104.302 & 248.028 & 273.860 & 0.036 & 0.056 & 0.062 \\
XJ & 2.514 & 3.879 & 4.253 & 209.447 & 317.023 & 327.933 & 0.080 & 0.098 & 0.105 \\
TP & 3.649 & 5.012 & 5.385 & 192.961 & 295.236 & 307.554 & 0.084 & 0.098 & 0.104 \\
DX & 2.053 & 3.399 & 3.772 & 226.367 & 335.816 & 346.401 & 0.062 & 0.083 & 0.091 \\
CGZ & 2.057 & 3.079 & 3.451 & 298.816 & 414.159 & 419.598 & 0.086 & 0.108 & 0.117 \\
NM & 1.735 & 2.961 & 3.330 & 252.017 & 354.912 & 362.313 & 0.090 & 0.108 & 0.115 \\
XMQ & 0.320 & 0.890 & 1.264 & 65.198 & 173.005 & 215.478 & 0.020 & 0.035 & 0.037 \\
WZ & 0.712 & 1.324 & 1.699 & 120.968 & 216.803 & 252.321 & 0.029 & 0.043 & 0.048 \\
MQ & 2.087 & 2.869 & 3.240 & 378.122 & 450.370 & 451.363 & 0.117 & 0.120 & 0.125 \\
CLJ & 2.183 & 2.993 & 3.365 & 299.140 & 396.235 & 404.646 & 0.146 & 0.191 & 0.197 \\
WXJ & 2.616 & 3.304 & 3.665 & 445.607 & 455.775 & 474.793 & 0.330 & 0.345 & 0.363 \\
XBB & 1.706 & 2.424 & 2.777 & 370.348 & 440.865 & 442.206 & 0.090 & 0.093 & 0.103 \\
MHK & 1.546 & 2.659 & 3.031 & 291.821 & 400.272 & 404.046 & 0.087 & 0.111 & 0.118 \\
WEZ & 1.139 & 1.857 & 2.222 & 212.028 & 315.534 & 331.058 & 0.043 & 0.051 & 0.055 \\
CG & 0.900 & 1.599 & 1.956 & 275.259 & 357.360 & 362.860 & 0.044 & 0.048 & 0.051 \\
\hline
\end{tabular}

\section{Vulnerability}

Taking Chengguan town in Huaiyuan county (CG) as an example, the original values of indicators in the Table 1 could be uniformly normalized and transformed into positive indicators in the range of [0,1], as shown in Table 5. 
Table 5. Normalized values of indicators of $C G$.

\begin{tabular}{c|c|c|c}
\hline Target layer & Criterion layer & Index layer & $\begin{array}{c}\text { Normalized } \\
\text { values }\end{array}$ \\
\hline \multirow{4}{*}{} & & GDP per unit area (C1) & 0.2374 \\
& Exposure degree (B1) & Density of population (C2) & 0.5181 \\
& & Density of residential structures (C3) & 1 \\
\cline { 2 - 4 } & & Density of lifeline engineering structures (C4) & 0 \\
\hline \multirow{4}{*}{$\begin{array}{c}\text { Vulnerability } \\
\text { of CG (A) }\end{array}$} & Sensibility (B2) & Average elevation (C5) & 0.1270 \\
& & Proportion of agricultural population (C6) & 0 \\
& & Land-use sensitive index (C7) & 0 \\
\cline { 2 - 4 } & Capacity of disaster & GDoportion of female population (C8) & 0.7234 \\
\cline { 2 - 4 } & prevention and mitigation & Density of shelters (C10) & 0.7842 \\
& (B3) & Density of medical aid institutions (C11) & 0.3370 \\
& & &
\end{tabular}

$\mathrm{C} 1, \mathrm{C} 2, \mathrm{C} 3, \mathrm{C} 4$ in index layer could constitute a cusp catastrophe:

$$
\begin{aligned}
& X_{\mathrm{c} 1}=\mathrm{C} 1^{1 / 2}=(0.2374)^{1 / 2}=0.4872 \\
& X_{\mathrm{c} 2}=\mathrm{C} 2^{1 / 3}=(0.5181)^{1 / 3}=0.8032 \Rightarrow B 1=\left(X_{\mathrm{c} 1}+X_{\mathrm{c} 2}+X_{\mathrm{c} 3}+X_{\mathrm{c} 4}\right) / 4=0.5726 \\
& X_{\mathrm{c} 3}=\mathrm{C} 3^{1 / 4}=(1)^{1 / 4}=1 \\
& X_{\mathrm{c} 4}=\mathrm{C} 4^{1 / 5}=(0)^{1 / 5}=0
\end{aligned}
$$

C5, C6, C7, C8 in index layer could constitute a cusp catastrophe:

$$
\begin{aligned}
& X_{\mathrm{c} 5}=\mathrm{C} 5^{1 / 2}=(0.1270)^{1 / 2}=0.3564 \\
& X_{\mathrm{c} 6}=\mathrm{C}^{1 / 3}=(0)^{1 / 3}=0 \\
& X_{\mathrm{c} 7}=\mathrm{C} 7^{1 / 4}=(0)^{1 / 4}=0 \\
& X_{\mathrm{c} 8}=\mathrm{C} 8^{1 / 5}=(0.7234)^{1 / 5}=0.9373
\end{aligned} \quad \Rightarrow B 2=\left(X_{\mathrm{c} 5}+X_{\mathrm{c} 6}+X_{\mathrm{c} 7}+X_{\mathrm{c} 8}\right) / 4=0.3234
$$

C9, C10, C11 in index layer could constitute a swallowtail catastrophe:

$$
\begin{aligned}
& X_{\mathrm{c} 9}=\mathrm{C} 5^{1 / 2}=(0.7842)^{1 / 2}=0.8856 \\
& X_{\mathrm{c} 10}=\mathrm{C} 6^{1 / 3}=(0.3370)^{1 / 3}=0.6959 \\
& X_{\mathrm{c} 11}=\mathrm{C} 7^{1 / 4}=(0.6687)^{1 / 4}=0.9043
\end{aligned} \quad \Rightarrow B 3=\left(X_{\mathrm{c} 9}+X_{\mathrm{c} 10}+X_{\mathrm{c} 11}\right) / 3=0.8286
$$

B1, B2, B3 in criterion layer could constitute a swallowtail catastrophe:

$$
\begin{aligned}
& X_{\mathrm{B} 1}=\mathrm{B} 1^{1 / 2}=0.7567 \\
& X_{\mathrm{B} 2}=\mathrm{B} 2^{1 / 3}=0.6864 \\
& X_{\mathrm{B} 3}=\mathrm{B} 3^{1 / 4}=0.9541
\end{aligned} \Rightarrow A=\left(X_{\mathrm{B} 1}+X_{\mathrm{B} 2}+X_{\mathrm{B} 3}\right) / 3=0.7991
$$


Thus, the value of vulnerability to flood of CG is 0.7991 and the rest of townships could be calculated by analogy. The results are shown in Table 6 .

Table 6. The values of vulnerability of each evaluation township

\begin{tabular}{c|c|c|c|c}
\hline Evaluation township & Exposure degree (B1) & Sensibility (B2) & $\begin{array}{c}\text { Capacity of disaster } \\
\text { prevention and } \\
\text { mitigation (B3) }\end{array}$ & Vulnerability \\
\hline HN & 0.5860 & 0.7926 & 0.9770 & 0.8951 \\
XJ & 0.6429 & 0.8860 & 0.9221 & 0.9141 \\
TP & 0.6487 & 0.9508 & 0.9695 & 0.9270 \\
DX & 0.6435 & 0.8265 & 0.9355 & 0.9081 \\
CGZ & 0.6011 & 0.7284 & 0.9599 & 0.8883 \\
NM & 0.4640 & 0.7569 & 0.9478 & 0.8598 \\
XMQ & 0.6017 & 0.6950 & 0.9717 & 0.8848 \\
WZ & 0.5251 & 0.8670 & 0.9465 & 0.8882 \\
MQ & 0.5135 & 0.6281 & 0.9107 & 0.8499 \\
CLJ & 0.6720 & 0.8563 & 0.9589 & 0.9196 \\
WXJ & 0.7789 & 0.8573 & 0.5443 & 0.8971 \\
XBB & 0.9346 & 0.7053 & 0.1913 & 0.8394 \\
MHK & 0.7169 & 0.8669 & 0.9446 & 0.9287 \\
WEZ & 0.3928 & 0.6344 & 0.9879 & 0.8277 \\
CG & 0.5726 & 0.3234 & 0.8286 & 0.7991 \\
\hline
\end{tabular}

Vulnerability were classified into five magnitudes (micro vulnerability, light vulnerability, medium vulnerability, high vulnerability and severe vulnerability) by natural breakpoint method in ArcGIS (Wu and Li, 2013). The ranges of values for each level were [0.7991, 0.8277], [0.8394, 0.8598], [0.8848, 0.8971], [0.9081, 0.9141], [0.9196, 0.9287], respectively. The spatial distribution of the magnitudes of vulnerability in the study area is shown in Figure 6.

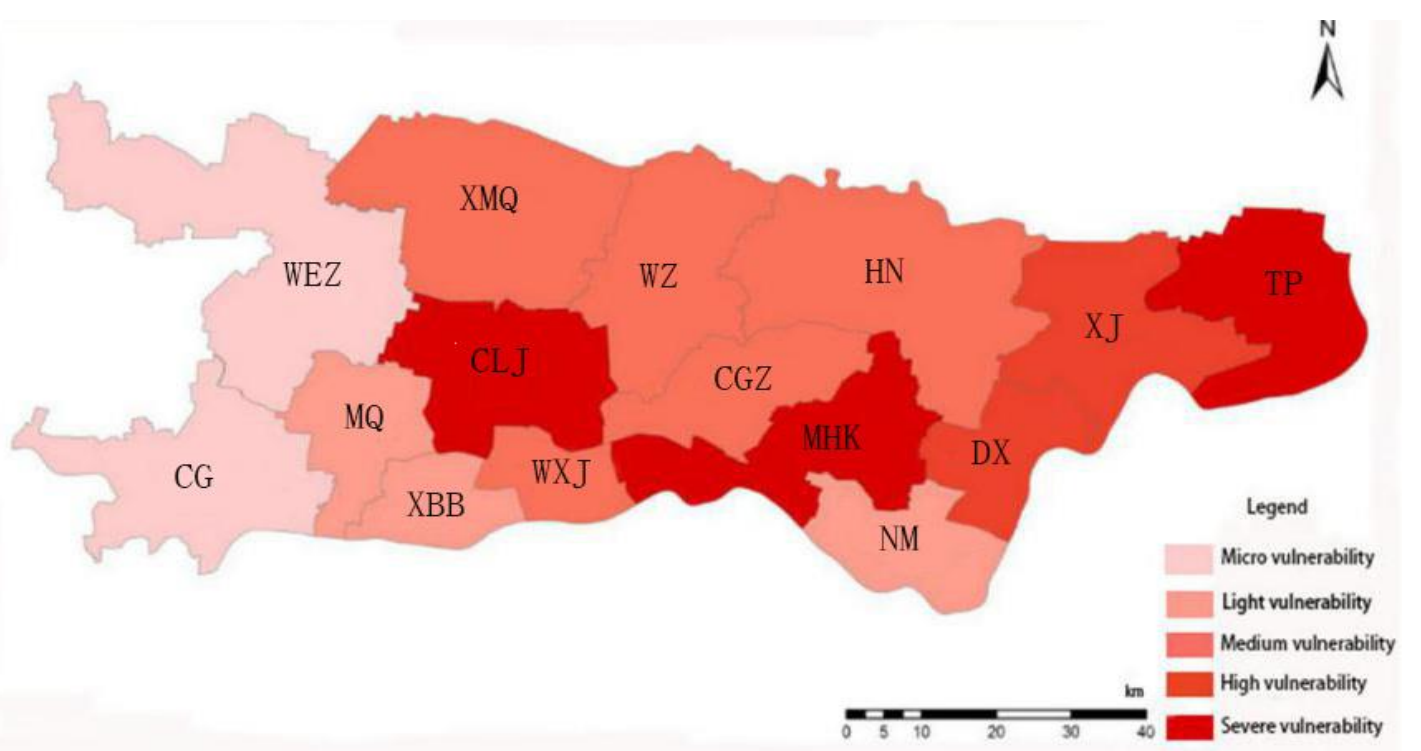

Figure 6. Spatial distribution of the magnitudes of vulnerability in the study area 


\section{Risk}

We standardized the original values of the indicators in flood risk index system (include 13 evaluation indicators and 15 evaluation objects) as the matrix firstly. Through factor analysis, it could be found that the accumulated contribution of variances of the first three factors could reach to $82.78 \%$ (close to $85 \%$ ), so they were extracted as common factors to summarize the information provided by the original indicators. As computed, $\mathrm{C}_{1} / \mathrm{C}=0.6357 ; \quad \mathrm{C}_{2} / \mathrm{C}=0.2057 ; \quad \mathrm{C}_{3} / \mathrm{C}=0.1586$, the comprehensive flood risk score ' $\mathrm{S}$ ' of each evaluation township is presented in Table 7. With the application of hierarchical clustering analysis, the clustering dendrogram of evaluation townships was drawn by MATLAB, as shown in Figure 7. Based on Figure 7, we classified the flood risk in HHS into 6 magnitudes, as shown in Table 7.

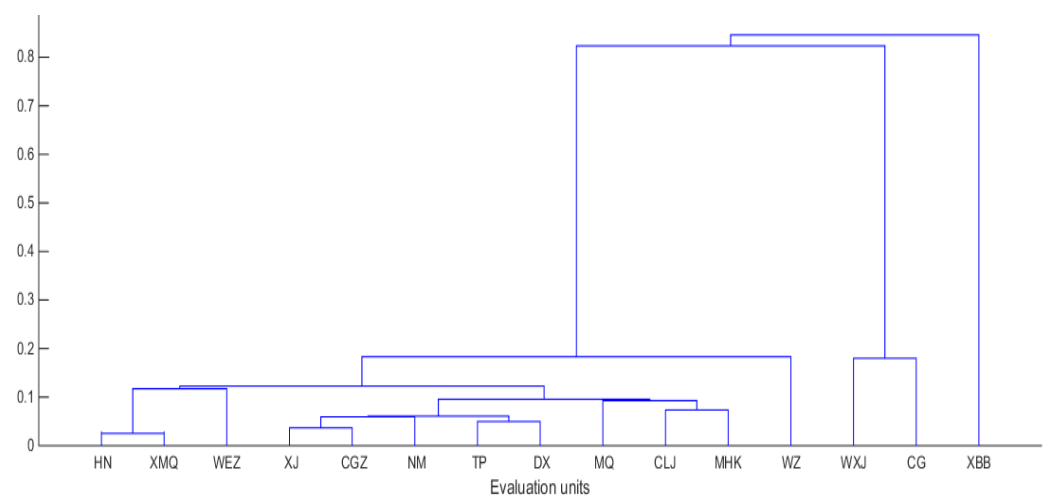

Figure 7. The clustering dendrogram of evaluation townships

Table 7. The comprehensive flood risk score 'S' and the magnitudes of the flood risk of these evaluation townships

\begin{tabular}{c|c|c|c}
\hline $\begin{array}{c}\text { Evaluation } \\
\text { township }\end{array}$ & $\begin{array}{c}\text { Comprehensive flood risk } \\
\text { score (S) }\end{array}$ & $\begin{array}{c}\text { Vulnerability index } \\
\text { value }\end{array}$ & $\begin{array}{c}\text { Magnitude of flood } \\
\text { risk }\end{array}$ \\
\hline HN & -0.509 & 0.8951 & Low-risk \\
XJ & -0.326 & 0.9141 & Low-medium-risk \\
TP & -0.253 & 0.9270 & Low-medium-risk \\
DX & -0.207 & 0.9081 & Low-medium-risk \\
CGZ & -0.300 & 0.8883 & Low-medium-risk \\
NM & -0.248 & 0.8598 & Low-medium-risk \\
XMQ & -0.532 & 0.8848 & Low-risk \\
WZ & -0.715 & 0.8882 & Medium-high-risk \\
MQ & 0.010 & 0.8499 & Medium-risk \\
CLJ & -0.112 & 0.9196 & Medium-risk \\
WXJ & 0.832 & 0.8971 & High-risk \\
XBB & 1.828 & 0.8394 & Extremely-high-risk \\
MHK & -0.039 & 0.9287 & Medium-risk \\
WEZ & -0.413 & 0.8277 & Low-risk \\
CG & 0.983 & 0.7991 & High-risk \\
\hline
\end{tabular}




\section{Discussion}

The results of the research show that the flood risk in most areas of HHS is medium or even higher, which are consistent with the facts (Guo and Zha, 2010; Zhang, 2018; Huang et al., 2011). Huang et al. (2011) demonstrated that the flood disaster prevention and mitigation capacity of areas in the south of the main stream of Huaihe River was relatively low. Most areas of HHS are in medium, high even severe vulnerability which calculated in this article corroborates the study by Huang et al. (2011). The hypothesis used in this study that the flood risk is a combination of the natural hazard and vulnerability which was schematized in an equation: Risk $=$ Hazard $\times$ Vulnerability (Wisner et al., 2003; Kubal et al., 2009).

One of the planned extensions to the integrated method is a more comprehensive index system of flood risk assessment, which will inevitably involve more relevant regional indicators inputs associated with, for example, average age of population, type of housing and traffic situation in the region. In theory, the more considerate the indicators are, the more reliable the results become. A further possibility that could be considered for future development of the integrated method is to identify the evaluation units. The present-day results of flood risk are not completely actual because the administrative units (townships) are not the actual space units of flooding influence, thus it is difficult to distinguish the magnitudes of flood risk within a township. To a certain extent, this restricts the applicability of the integrated method in a small region. Besides, in the process of a flood, there is usually more than one breach in the floodplain. Therefore, the flood risk analysis considering multiple breaches is another future research direction to be supplemented and improved.

\section{Conclusions}

This paper fully understands the flood risk, considering that when assessing the flood risk for a specific region, we should investigate the flood hazard factors and different vulnerability indicators of the region at risk. In flood hazard analysis, a 1-D and 2-D coupled hydrodynamic model was established through MIKE software and used to simulate the floods with various return periods for obtaining the data of the flood hazard factors, such as inundation depth, inundation duration and flood flow velocity. In vulnerability analysis, according to the vulnerability evaluation index system of the object at flood risk, the catastrophe progression method was used to calculate the index value of vulnerability. Combining the flood hazard factors under the 200-year flood with the vulnerability indicators to flood disasters in HHS, a relatively complete index system of flood risk under the current conditions was established, and the flood risk were classified into 6 magnitudes by the method of factor analysis and hierarchical cluster analysis. The results are as follows:

The values of inundation depth, inundation duration and flood flow velocity of evaluation townships under 50-year, 100-year and 200-year floods in HHS show an increasing trend following the increasing return periods. When faced with the 50-year flood, the maximum inundation depth can reach $3.649 \mathrm{~m}$ and the maximum inundation duration can reach about $446 \mathrm{~h}$. When faced with the 100-year flood, the maximum inundation depth can reach $3.879 \mathrm{~m}$ and the maximum inundation duration can reach about $456 \mathrm{~h}$. When faced with the 200-year flood, the maximum inundation depth can reach $4.253 \mathrm{~m}$ and the maximum inundation duration can reach about $475 \mathrm{~h}$. 
According to the spatial distribution map of the magnitudes of vulnerability, vulnerability in most areas of HHS towards flood disasters is high.

Among the 15 townships evaluated, XBB is an extremely high-risk zone, WXJ and CG are the high-risk zones, WZ is the medium-high-risk areas, MQ, CLJ, MHK are the medium-risk zones, while XJ, TP, DX, CGZ, NM are the low-medium-risk zones. HN, XMQ and WEZ are low-risk zones.

Acknowledgements. The authors would like to acknowledge the Associate Editor and two anonymous reviewers for providing useful and constructive comments. Special thanks to Zhang, Z. X. and Wu, J. J. for their contribution to this research. This paper is supported by Natural Science Foundation of Jiangsu Province of China (Program No. BK20181310) and the Fundamental Research Funds for the Central Universities of China (Program No. 2019B45314).

\section{REFERENCES}

[1] Apel, H., Aronica, G. T., Kreibich, H., Thieken, A. H. (2009): Flood risk analyses - how detailed do we need to be? - Nat Hazards 49: 79-98.

[2] Baldassarre, G. D., Castellarin, A., Montanari, A., Brath, A. (2009): Probability-weighted hazard maps for comparing different flood risk management strategies: a case study. Natural Hazards 50(3): 479-496.

[3] Brandimarte, L., Di Baldassarre, G. (2012): Uncertainty in design flood profiles derived by hydrodynamic modelling. - Hydrology Research 43(6): 753-761.

[4] Chen, P., Wang, X. L., Chen, X. L. (2012): Spatio-temporal variation of flood vulnerability at the Poyang Lake Ecological Economic Zone, Jiangxi Province, China. Water Science \& Technology 65(7): 1332.

[5] Cook, A., Merwadee, V. (2009): Effect of topographic data, geometric configuration and modeling approach on flood inundation mapping. - Journal of Hydrology 377: 131-142.

[6] Fan, Y. X., Luo, Y., Chen, Q. S. (2000): Discussion on quantitative method of disasterbearing body vulnerability evaluation index. - Journal of Catastrophology 15(2): 78-81.

[7] Ferdous, A. (2012): A hydrologic model of Kemptville Basin—calibration and extended validation. - Water Resources Management 26(9): 2583-2604.

[8] Fuchs, S., Birkmann, J., Glade, T. (2012): Vulnerability assessment in natural hazard and risk analysis: current approaches and future challenges. - Natural Hazards 64(3): 19691975.

[9] Guo, Y. F., Zha, L. S. (2010): Risk regionalization of flood and waterlogging disaster and analysis of variation tendency of damaged area in Anhui province. - Chinese Journal of Agrometeorology 31(1): 130-136.

[10] Helena, B., Pardo, R., Vega, M., Barrado, E., Fernandez, J. M., Fernandez, L. (2000): Temporal evolution of groundwater composition in an alluvial aquifer (Pisuerga River, Spain) by principal component analysis. - Water Research 34(3): 0-816.

[11] Horritt, M. S., Bates, P. D. (2002): Evaluation of 1-D and 2-D numerical models for predicting river flood inundation. - Journal of Hydrology 268(1-4): 87-99.

[12] Huang, D. P., Zheng, W., Zhang, R. H., Huo, Z. G., Li, J. L., Peng, S. F. (2011): Assessment of capacity of flood disaster prevention and reduction of Huaihe River Basin in Anhui Province. - Geographical Research 30(3): 523-530.

[13] Jungkyu, A., Yeji, N., Sung, W. P. (2019): Development of two-dimensional inundation modelling process using MIKE21 model. - KSCE Journal of Civil Engineering 23(9): 3368-3977.

[14] Kourgialas, N. N., Karatzas, G. P. (2011): Flood management and a GIS modelling method to assess flood-hazard areas - a case study. - Hydrological Sciences Journal 56(2): 212-225. 
[15] Kubal, C., Haase, D., Meyer, V., Scheuer, S. (2009): Integrated urban flood risk assessment - adapting a multicriteria approach to a city. - Natural Hazards and Earth System Science 9(6): 1881-1895.

[16] Kuo, Y. M., Jang, C. S., Yu, H. L., Chen, S. C., Chu, H. J. (2013): Identifying near shore groundwater and river hydrochemical variables influencing water quality of Kaoping River Estuary using dynamic factor analysis. - Journal of Hydrology 486(4): 39-47.

[17] Li, B., Pu, P. M., Han, A. M. (2003): Factor Analysis of Water Quality in Hongze Lake. China Environmental Science Press, Beijing, pp. 70-74.

[18] Li, S. F., Feng, P., Sun, S. H. (2010): Application of catastrophe theory in flood risk assessment in flood storage and detention areas. - Journal of Natural Disasters 19(3): 132-138.

[19] Liu, J. T., Gao, J. F., Jiang, J. H., Xu, Y., Zhao, J. H. (2010): Zoning assessment of cyanobacterial blooms in Taihu Lake based on Catastrophe Theory. - Journal of Lake Sciences 4: 488-494.

[20] Ma, R., Shi, J. S. (2011): Assessing groundwater pollution using fuzzy factor analysis method: a case study of Luoyang City in Henan Province. - Acta Geoscientica Sinica 32(5): 611-622.

[21] Masood, M., Takeuchi, K. (2012): Assessment of flood hazard, vulnerability and risk of mid-eastern Dhaka using DEM and 1-D hydrodynamic model. - Natural Hazards 61(2): 757-770.

[22] Merz, B., Hall, J., Disse, M., Schumann, A. (2010): Fluvial flood risk management in a changing world. - Natural Hazards \& Earth System Sciences 10(3): 509-527.

[23] Muangthong, S., Shrestha, S. (2015): Assessment of surface water quality using multivariate statistical techniques: case study of the Nampong River and Songkhram River, Thailand. - Environmental Monitoring \& Assessment 187(9): 548.

[24] Parto, S., Chatterjee, C., Mohanty, S., Singh, R., Raghuwanshi, N. S. (2009): Flood inundation modeling using MIKE FLOOD and remote sensing data. - Journal of the Indian Society of Remote Sensing 37(1): 107-118.

[25] Tewodros, A. N., Abdusselam, A. (2019): Modeling the effect of urbanization on flood risk in Ayamama Watershed, Istanbul, Turkey, using the MIKE 21 FM model. - Natural Hazards 99(2): 1031-1047.

[26] Van Alphen, J., Martini, F., Looat, R., Slomp, R., Passchier, R. (2009): Flood risk mapping in Europe, experiences and best practices. - Journal of Flood Risk Management 2: $285-292$.

[27] Wan, J., Bu, H., Zhang, Y., Meng, W. (2013): Classification of rivers based on water quality assessment using factor analysis in Taizi River basin, northeast China. Environmental Earth Sciences 69(3): 909-919.

[28] Wang, Y. Z. (2015): Waterlogging Disaster and its Control in Huaihe River Basin. Science Press, Beijing.

[29] Wisner, B., Blaikie, P., Cannon, T., Davis, I. (2003): At risk: natural hazards, people's vulnerability and disasters. - Econ. Geography 72(4): 460-463.

[30] Wu, H. Z., Li, T. (2013): The comprehensive performance evaluation of the high-tech development zone: analysis based on natural breakpoint method. - Statistics \& Information Forum 28(3): 82-88.

[31] Yu, L., Xu, Y., Zhang, Y. X. (2018): Temporal and spatial variation of rainstorms and the impact of flood disasters due to rainstorms in China in the past 25 years. - Torrential Rain and Disasters 37(1): 67-72.

[32] Zhang, F. H., Cui, Q. L., Chen, L. J. (2019): Analysis of flood risk of the flood-protected area of lower Weihe River. - Yellow River 41(9): 65-69.

[33] Zhang, L., Wang, J. Q., Yang, F. R., Li, K. Q. (2009): Factor analysis and fuzzy clustering of driver behavior pattern. - Journal of Transportation Engineering 9(5): 121126. 
[34] Zhang, Z. (2018): Research and development of flood analysis model subsystem that be part of the decision risk management system for flood discharge and retention zones in Huaihe river of Anhui province. - Pearl River 39(6): 101-106 + 112. 